\title{
Development, external validation and clinical usefulness of a practical prediction model for radiation-induced dysphagia in lung cancer patients
}

Citation for published version (APA):

Dehing-Oberije, C., De Ruysscher, D., Petit, S., Van Meerbeeck, J., Vandecasteele, K., De Neve, W., Dingemans, A. M. C., El Naqa, I., Deasy, J. O., Bradley, J., Huang, E., \& Lambin, P. (2010). Development, external validation and clinical usefulness of a practical prediction model for radiation-induced dysphagia in lung cancer patients. Radiotherapy and Oncology, 97(3), 455-461.

https://doi.org/10.1016/j.radonc.2010.09.028

Document status and date:

Published: 01/12/2010

DOI:

10.1016/j.radonc.2010.09.028

Document Version:

Publisher's PDF, also known as Version of record

\section{Document license:}

Taverne

Please check the document version of this publication:

- A submitted manuscript is the version of the article upon submission and before peer-review. There can be important differences between the submitted version and the official published version of record.

People interested in the research are advised to contact the author for the final version of the publication, or visit the DOI to the publisher's website.

- The final author version and the galley proof are versions of the publication after peer review.

- The final published version features the final layout of the paper including the volume, issue and page numbers.

Link to publication

\footnotetext{
General rights rights.

- You may freely distribute the URL identifying the publication in the public portal. please follow below link for the End User Agreement:

www.umlib.nl/taverne-license

Take down policy

If you believe that this document breaches copyright please contact us at:

repository@maastrichtuniversity.nl

providing details and we will investigate your claim.
}

Copyright and moral rights for the publications made accessible in the public portal are retained by the authors and/or other copyright owners and it is a condition of accessing publications that users recognise and abide by the legal requirements associated with these

- Users may download and print one copy of any publication from the public portal for the purpose of private study or research.

- You may not further distribute the material or use it for any profit-making activity or commercial gain

If the publication is distributed under the terms of Article $25 \mathrm{fa}$ of the Dutch Copyright Act, indicated by the "Taverne" license above, 
Lung cancer radiotherapy

\title{
Development, external validation and clinical usefulness of a practical prediction model for radiation-induced dysphagia in lung cancer patients
}

\author{
Cary Dehing-Oberije ${ }^{\mathrm{a}, *}$, Dirk De Ruysscher ${ }^{\mathrm{a}}$, Steven Petit ${ }^{\mathrm{a}}$, Jan Van Meerbeeck ${ }^{\mathrm{b}}$, Katrien Vandecasteele ${ }^{\mathrm{c}}$, \\ Wilfried De Neve ${ }^{c}$, Anne Marie C. Dingemans ${ }^{d}$, Issam El Naqa ${ }^{e}$, Joseph Deasy ${ }^{e}$, Jeff Bradley ${ }^{\mathrm{e}}$, Ellen Huang ${ }^{\mathrm{e}}$, \\ Philippe Lambin ${ }^{\mathrm{a}}$
}

${ }^{a}$ Department of Radiotherapy, Maastricht University Medical Center, University Maastricht, MAASTRO clinic, GROW, The Netherlands; ${ }^{\mathrm{b}}$ Lung Oncological Network Ghent (LONG); and ${ }^{\mathrm{c}}$ Department of Radiotherapy, University Hospital Ghent, Belgium; ${ }^{\mathrm{d}}$ Department of Pulmonology, Maastricht University Medical Center, The Netherlands; ${ }^{\mathrm{e}}$ Department of Radiation Oncology, Washington University in St. Louis, St. Louis, MO, USA

\section{A R T I C L E I N F O}

\section{Article history:}

Received 16 June 2010

Received in revised form 23 September

2010

Accepted 26 September 2010

\section{Keywords:}

Dysphagia

Nomogram

Prediction model

Lung cancer

\begin{abstract}
A B S T R A C T
Introduction: Acute dysphagia is a distressing dose-limiting toxicity occurring frequently during concurrent chemo-radiation or high-dose radiotherapy for lung cancer. It can lead to treatment interruptions and thus jeopardize survival. Although a number of predictive factors have been identified, it is still not clear how these could offer assistance for treatment decision making in daily clinical practice. Therefore, we have developed and validated a nomogram to predict this side-effect. In addition, clinical usefulness was assessed by comparing model predictions to physicians' predictions.

Materials and methods: Clinical data from 469 inoperable lung cancer patients, treated with curative intent, were collected prospectively. A prediction model for acute radiation-induced dysphagia was developed. Model performance was evaluated by the c-statistic and assessed using bootstrapping as well as two external datasets. In addition, a prospective study was conducted comparing model to physicians' predictions in 138 patients.

Results: The final multivariate model consisted of age, gender, WHO performance status, mean esophageal dose (MED), maximum esophageal dose (MAXED) and overall treatment time (OTT). The c-statistic, assessed by bootstrapping, was 0.77. External validation yielded an AUC of 0.94 on the Ghent data and 0.77 on the Washington University St. Louis data for dysphagia $\geqslant$ grade 3 . Comparing model predictions to the physicians' predictions resulted in an AUC of 0.75 versus 0.53 , respectively.

Conclusions: The proposed model performed well was successfully validated and demonstrated the ability to predict acute severe dysphagia remarkably better than the physicians. Therefore, this model could be used in clinical practice to identify patients at high or low risk.
\end{abstract}

(C) 2010 Elsevier Ireland Ltd. All rights reserved. Radiotherapy and Oncology 97 (2010) 455-461
Acute dysphagia is a distressing, dose-limiting toxicity occurring in up to $40 \%$ of patients receiving concurrent chemo-radiation or up to $20 \%$ after high-dose radiotherapy alone for lung cancer $[1,2]$. It can lead to infections, hospitalizations, treatment interruptions and, therefore, decreased survival and increased costs. Identification of patients at high risk for developing this side-effect would make it possible to take adequate measures, such as placement of a nasogastric tube or, in the future, administration of preventive medication. On the other hand, patients with a low risk could be suitable for dose-escalation of the radiotherapy treatment, possibly resulting in higher local tumor control rates.

\footnotetext{
* Corresponding author. Address: Maastricht University Medical Center, University Maastricht, MAASTRO Clinic, Department of Radiotherapy, Dr. Tanslaan 12, 6229 ET Maastricht, GROW, The Netherlands.

E-mail address: cary.oberije@maastro.nl (C. Dehing-Oberije).
}

In studies that investigated clinical and dosimetric predictors of esophageal toxicity, results for age and gender have been inconsistent $[1,3-9]$ while performance status was not found to be a significant prognostic factor $[4,7,8]$. The use of concurrent chemotherapy with radiotherapy has been consistently identified as one of the main predictors for acute esophagitis $[1,10,11]$.

Numerous dosimetric parameters have been previously investigated $[2,10]$ including single number parameters derived from the continuously distributed dose-volume histogram (DVH), such as the $V_{\text {dose }}$ (e.g. $V_{20}$ or $V_{25}$ ) which is defined as the percentage of CT-defined total esophagus volume receiving a higher or equal dose compared to the threshold dose (e.g. 20 or $25 \mathrm{~Gy}$ ), parameters for the surface area $\left(S A_{20 G y}, S A_{30 G y}\right)$, the length of esophagus included in the radiation field $\left(L E T T_{20 G y}, L E T T_{30 G y}\right)$, mean esophageal dose, maximum esophageal dose, as well as more complex normal tissue complication probability (NTCP) models [11,12]. Many of these parameters are strongly inter-related. Although all studies 
have found different dosimetric parameters to be correlated with esophagitis or dysphagia, the majority of studies found MED to be associated with toxicity [2].

While a number of predictive factors associated with dysphagia have been identified it is still not clear how these factors should be used in daily clinical practice. Moreover, in order to offer assistance for treatment decision making, a prediction model should at least perform better than the physicians themselves. However, studies assessing the ability of physicians to predict toxicity outcome are, to the best of our knowledge, still lacking.

Therefore, we decided to develop a nomogram to predict acute severe dysphagia in lung cancer patients who are receiving radiotherapy alone or combined with chemotherapy, using treatment and patient characteristics of a large group of patients. In addition, the model was externally validated in two large European and North-American datasets and its clinical usefulness was assessed by prospectively comparing the model to physicians' predictions.

\section{Materials and methods}

\section{Patient population}

Between January 2004 and May 2009, 617 patients with medically or technically inoperable non-small cell lung cancer (NSCLC), stage I-IIIB, or small cell lung cancer (SCLC), stage I-IIIB (limited disease) were referred to the MAASTRO clinic to be treated with curative intent. A subgroup of 138 patients was included in a prospective study in which the doctors predicted the probability of severe dysphagia. These patients were, therefore, excluded from the development cohort and their data were not used in the model building procedure. Consequently, the development cohort consisted of 469 patients. Clinical data of all these patients were prospectively collected. Dosimetric parameters were calculated using a commercial radiotherapy treatment planning system (XiO, Computerized Medical Systems, St. Louis, MO, USA). The esophagus was delineated using the external esophageal contour from the cricoid cartilage to the GE junction. Toxicity was prospectively scored using the Dysphagia scale of the NCI Common Toxicity Criteria version 3.0 (CTCAEv3.0). For the statistical analysis the maximum dysphagia score at any time point during or at maximum 4 weeks after the end of radiotherapy was used.

\section{Treatment schedules}

Patients were treated in accordance to different a priori defined radiation and chemotherapy protocols according to the stage and the histology (NSCLC versus SCLC) of the disease.

All patients received radiation at MAASTRO clinic, the chemotherapy treatment was administered in the referring hospitals. No elective nodal irradiation was performed [13] and irradiation was delivered 5 days per week. Radiotherapy planning was performed with an XiO (Computerized Medical Systems, St. Louis, MO, USA) system, using a convolution-superposition algorithm with inhomogeneity corrections and according to ICRU 50 guidelines [14].

Four different radiotherapy treatment regimes were administered.

(1) One hundred ten NSCLC patients were treated according to the standard protocol used until August 2005. They received either $70 \mathrm{~Gy}$ (stage I-II) or $60 \mathrm{~Gy}$ after induction chemotherapy (stage III), in once daily fractions of $2 \mathrm{~Gy}$.

(2) Second, 231 NSCLC patients were treated according to the new protocol for sequential chemo-radiation, which was introduced in August 2005 [15-17]. The individualized radiation dose ranged from 54.0 to $79.2 \mathrm{~Gy}$, delivered in fractions of $1.8 \mathrm{~Gy}$, twice daily, depending on the mean lung dose or the spinal cord dose constraint. Eight hours interval between the fractions was respected.

(3) Thirty-one NSCLC patients received concurrent chemo radiotherapy [18]. After two cycles of carboplatin-gemcitabine, a radiation dose of $45 \mathrm{~Gy}$ was delivered in fractions of $1.5 \mathrm{~Gy}$, twice daily, followed by an individualized dose ranging from 8 to $24 \mathrm{~Gy}$, delivered in fractions of $2.0 \mathrm{~Gy}$, once daily. Cisplatin-vinorelbine was given concurrently on days $2,9,23$ and 30 .

(4) Finally, 97 SCLC patients were treated according to the standard protocol for this disease. They received $45 \mathrm{~Gy}$, delivered in fractions of $1.5 \mathrm{~Gy}$, twice daily, concurrently with carboplatin or cisplatin combined with etoposide, but without elective nodal irradiation $[19,20]$. Patients without disease progression received thereafter a profylactic cranial irradiation $(\mathrm{PCI})$.

\section{Statistical analysis}

Ordinal logistic regression was used to build a multivariate model to predict dysphagia. The use of this method for analysis of graded toxicity data has been discussed previously [21]. Briefly, grade of dysphagia is an ordinal variable, i.e. higher grades correspond to more severe side effects. However, no numerical relationship is assumed between these ordered categories. Using the ordinal outcome instead of reducing this outcome to a binary response improves the statistical power. The obtained model coefficients can be used afterwards to calculate the probability for an individual patient for each outcome category. In this case the proportional odds model was used. This model assumes that the odds ratio for each predictor is constant across all possible collapsing of the response variable. As dosimetric parameters are often highly correlated, variable selection can be rather arbitrary, leading to unrobust models $[22,23]$. Therefore, the number of dosimetric parameters included in the initial model was limited. According to a recently published review, the most consistently found dosimetric parameter is the mean esophagus dose (MED) [2]. Taking into account that the maximum esophagus dose (MAXED) was also identified as a predictor of dysphagia in several studies [2] and was not highly correlated with MED, we decided to enter MED and MAXED into the initial model. For all variables single imputation was used if the value was missing. Stepwise backward variable selection was performed, removing variables with a $p$-value $\geqslant 0.2$ from the model. In addition, interaction terms were tested as well as the ordinality assumption. Odds ratios (OR) and the $95 \%$ confidence intervals were reported. The performance of the model was studied with respect to calibration and discrimination. Calibration was studied graphically and refers to the agreement between the observed frequencies and the predicted probabilities. Discriminative ability, i.e. whether the relative ranking of individual predictions is in the correct order, was determined with the concordance c-statistic. The interpretation of the c-statistic is comparable to the interpretation of the Area Under the Curve (AUC) of the Receiver Operator Curve (ROC) and can be applied to ordinal regression models. The maximum value of the c-statistic is 1.0 ; indicating a perfect prediction model. A value of 0.5 indicates that patients are correctly classified in $50 \%$ of the cases, e.g. as good as chance. Bootstrapping techniques were used to adjust the estimated model performance for overfitting [23]. The c-statistic of the final multivariate model was reported. A nomogram, which is a graphical representation of the multivariate model, was made for practical use. Each effect in the model is converted into a 0 100 scale which is just proportional to the log odds. These points are added across predictors to derive the "Total Points", which 
are converted into a predicted probability. In addition, the statistical formula was also implemented in a spreadsheet, which is available on the internet (www.predictcancer.org). External validation of the model was performed using data from Ghent University Hospital as well as Washington University in St. Louis (WUSTL). Finally, in a prospective study the prediction of the physicians was compared to the model prediction using data from a patient cohort treated at MAASTRO clinic. The analysis was performed with SPSS, version 15.0 (SPSS Inc., Chicago, IL) and $R$, version 2.8.1 ( $R$ foundation for statistical computing, Vienna, Austria).

\section{External validation cohorts}

The Ghent cohort consisted of 117 lung cancer patients with NSCLC, stage I-IIIB, or SCLC, limited disease. All patients were treated with curative intent in the period between May 2003 and December 2008. For the external validation 17 patients were excluded, because they received stereotactic radiotherapy.

The validation cohort of WUSTL consisted of 237 NSCLC patients, stage I-IIIB, treated with radiotherapy with or without chemotherapy in the period between 1991 and 2001. Twentyone patients were excluded, because they received sequential as well as concurrent chemotherapy. Data of both cohorts were collected prospectively.

\section{Prediction of the physicians}

A prospective study was conducted to assess the predictive ability of the physicians. Physicians were asked to indicate the probability that a patient would suffer from severe dysphagia, defined as dysphagia $\geqslant$ grade 3 according to the CTCV3.0 at two time points: (1) after a patient's first visit to the radiotherapy department and (2) after the radiotherapy treatment plan had been made. At time point 1 the physicians based their prediction on patient characteristics, staging information and diagnostic images (CT and PET), while at time point 2 the dose-volume histogram (DVH) was also available. All physicians were experienced radiotherapy oncologists, specialized in lung cancer. The probability was scored as a percentage. All patients included in this study had inoperable NSCLC, stage I-IIIB, or SCLC, limited disease, and were referred to MAASTRO clinic for radiation treatment with curative intent. Between September 2007 and May 2009 physicians predicted the probability of severe dysphagia for a total number of 138 patients. Data of this patient cohort were not used in the model building procedure.

\section{Ethics}

This study was conducted according to national laws and guidelines and was approved by the appropriate Institutional Review Board.

\section{Results}

\section{Univariate analysis}

Table 1 shows the characteristics of the development cohort as well as the external validation cohorts and the cohort included in the doctors' prediction study. Dysphagia $\geqslant$ grade 3 was scored in 52 cases $(11.1 \%)$ in the MAASTRO development cohort, 8 patients $(8 \%)$ of the Ghent cohort, 22 patients $(10.2 \%)$ of the WUSTL cohort and $16(11.1 \%)$ of the MAASTRO validation cohort. Comparison of the validation cohorts to the development cohort yielded statistically not significant results for histology (NSCLC versus SCLC) in the Ghent cohort, and toxicity grade in the WUSTL cohort. All other comparisons resulted in $p$-values $<0.05$, indicating that there were differences between the development cohort and the validation cohorts with regard to most patient characteristics.

\section{Multivariate analysis}

The set of predictor variables for the development of dysphagia consisted of age, gender, WHO performance status (PS), MED, MAXED, overall treatment time (OTT) and chemotherapy. None of the variables was removed from the model after the stepwise backward procedure. The odds ratios for developing dysphagia are shown in Table 2. The strongest predictors were MED, OTT and concurrent chemotherapy; OR 1.06 (95\% CI: 1.04-1.09, $p<0.001$ ), 0.94 (95\% CI: 0.92-0.96, $p<0.001$ ) and 2.53 (95\% CI: $1.64-3.91, p<0.001)$, respectively. Female gender, worse performance status, concurrent chemotherapy, shorter OTT, higher MED, higher MAXED and lower age were all associated with a higher risk of developing dysphagia. The c-statistic of the final model was 0.78 (95\% CI: 0.75-0.81), while the bootstrapping procedure resulted in a corrected c-statistic of 0.77 . The nomogram, based on the multivariate model, is shown in Fig. 1. The statistical formula was implemented in a spreadsheet, which is available on the internet (www.predictcancer.org). Filling out the required patient characteristics in the form yields a predicted probability and a $95 \%$ confidence interval for an individual patient.

\section{External validation}

External validation on the dataset from Ghent, using dysphagia $\geqslant$ grade 3 as outcome, resulted in an AUC of 0.94 while the AUC of the model on the WUSTL data was 0.77. Fig. 2 shows the calibration of the model. The ideal curve represents equality of observed frequencies and predicted probabilities. For the two subgroups of the Ghent cohort with the highest predicted probability the model slightly underestimates the actual probability while for the two subgroups of the WUSTL cohort with the highest predicted probability the model slightly overestimates the risk.

\section{Comparison of doctors' predictions to model predictions}

The ability of the physicians to predict dysphagia $\geqslant$ grade 3 at time point 1 was limited, resulting in an AUC of 0.53 (95\% CI: $0.37-0.67)$, while the prediction model performed well with an AUC of 0.75 (95\% CI: 0.63-0.86) (Fig. 3). The difference was statistically significant $(p=0.012)$. For time point 2 only 44 predictions were made. This was mainly due to logistic problems. Applying the prediction model to these 44 patients yielded an AUC of 0.86 (95\% CI: 0.40-0.95), while the AUC of the doctors' prediction was 0.72 (95\% CI: $0.63-1.0)$. The difference in this small subgroup was statistically not significant $(p=0.38)$.

\section{Discussion}

In this study, we developed and validated a prediction model for radiation-induced dysphagia. In addition, we showed that the model prediction outperformed the physicians' prediction. The final multivariate model, which resulted in a c-statistic of 0.77 , assessed by bootstrapping, consisted of age, gender, WHO performance status, chemotherapy, overall treatment time (OTT), mean esophagus dose (MED) and maximum esophagus dose (MAXED).

Many studies assessed the relationship between dosimetric parameters and radiation-induced dysphagia or esophagitis $[2,10]$. Different scales (e.g. Radiation Therapy Oncology Group (RTOG), NCI Common Toxicity Criteria, in-house developed esophagitis indices) $[9,11,24]$, as well as different cut points [11] have been used to assess esophageal toxicity. Moreover, delineation of the esophagus also differed between studies [2,11]. Therefore, comparison of studies and determination of dose constraints which should be used in clinical practice is difficult. However, MED has been found as a predictive factor in a majority of studies [2], while also MAXED was identified in a number of studies [2]. We, 
Table 1

Patient characteristics.

\begin{tabular}{|c|c|c|c|c|c|c|c|}
\hline & \multirow{2}{*}{$\begin{array}{l}\text { Development cohort } \\
\text { MAASTRO }(N=469)\end{array}$} & \multicolumn{5}{|l|}{ Validation cohort } & \multirow[t]{2}{*}{$P$} \\
\hline & & Ghent $(N=100)$ & $P$ & WUSTL $(N=216)$ & $P$ & MAASTRO $(N=138)$ & \\
\hline \multicolumn{8}{|l|}{ Gender } \\
\hline Male & $327(69.7 \%)$ & $82(82.0 \%)$ & 0.013 & $113(52.3 \%)$ & $<0.001$ & $77(55.8 \%)$ & 0.002 \\
\hline Female & $142(30.3 \%)$ & $18(18.0 \%)$ & & $103(47.7 \%)$ & & $61(44.2 \%)$ & \\
\hline Age (years) & Mean 68 (SD 10) & Mean 65 (SD 10) & 0.003 & Mean 66 (SD 12) & 0.03 & Mean 65 (SD 10) & 0.001 \\
\hline \multicolumn{8}{|l|}{ WHO-PS } \\
\hline 0 & $119(25.6 \%)$ & $20(20.4 \%)$ & & $194(89.8 \%)$ & $<0.001$ & $61(45.2 \%)$ & $<0.001$ \\
\hline 1 & $245(52.8 \%)$ & $78(79.6 \%)$ & & $22(10.2 \%)$ & & $61(45.2 \%)$ & \\
\hline$\geqslant 2$ & $100(21.6 \%)$ & - & & - & & $13(9.6 \%)$ & \\
\hline \multicolumn{8}{|l|}{ Histology } \\
\hline SCLC & $97(20.7 \%)$ & $21(21.0 \%)$ & 0.596 & - & & $26(18.8 \%)$ & 0.325 \\
\hline NSCLC & $316(67.4 \%)$ & $79(79.0 \%)$ & & $216(100 \%)$ & & $108(78.3 \%)$ & \\
\hline No histology & $56(11.9 \%)$ & - & & & & $4(2.8 \%)$ & \\
\hline TNM stage (NSCLC) & & NA & & NA & & & \\
\hline I & $86(23.6 \%)$ & & & & & $13(12.0 \%)$ & 0.003 \\
\hline II & $34(9.3 \%)$ & & & & & $6(5.6 \%)$ & \\
\hline IIIA & $79(21.7 \%)$ & & & & & $39(36.1 \%)$ & \\
\hline IIIB & $165(45.3 \%)$ & & & & & $50(46.3 \%)$ & \\
\hline \multicolumn{8}{|l|}{ Chemotherapy } \\
\hline No & $134(28.6 \%)$ & $18(18.0 \%)$ & 0.029 & $88(40.7 \%)$ & $<0.001$ & $24(17.4 \%)$ & $<0.001$ \\
\hline Sequential & 206 (43.9\%) & $43(43.0 \%)$ & & $62(28.7 \%)$ & & $28(20.3 \%)$ & \\
\hline Concurrent & $129(27.5 \%)$ & $39(39.0 \%)$ & & $66(30.6 \%)$ & & $86(62.3 \%)$ & \\
\hline OTT (days) & Mean 28.8 (SD 9.2) & Mean 44.4 (SD 10.2) & $<0.001$ & Mean 47.9 (SD 6.1) & $<0.001$ & Mean 26.9 (SD 6.7) & 0.023 \\
\hline & Range $16-60$ & Range $18-57$ & & Range 21-69 & & Range $16-46$ & \\
\hline MED (Gy) & Mean 20.7 (SD 10.8) & Mean 24.1 (SD 9.4) & 0.006 & Mean 30.8 (SD 14.8) & $<0.001$ & Mean 23.3 (SD 10.5) & 0.017 \\
\hline MAXED (Gy) & Mean 51.6 (SD 16.8) & Mean 57.1 (SD 12.4) & 0.004 & Mean 59.9 (SD 20.6) & $<0.001$ & Mean 54.8 (SD 9.6) & 0.055 \\
\hline \multicolumn{8}{|l|}{ CTC grade dysphagia } \\
\hline 0 & $142(30.3 \%)$ & $28(28.0 \%)$ & $<0.001$ & $74(34.2 \%)$ & 0.84 & $16(11.6 \%)$ & $<0.001$ \\
\hline 1 & $133(28.4 \%)$ & $53(53.0 \%)$ & & $57(26.4 \%)$ & & 55 (39.9\%) & \\
\hline 2 & $142(30.3 \%)$ & $11(11.0 \%)$ & & $63(29.2 \%)$ & & $51(37.0 \%)$ & \\
\hline$\geqslant 3$ & $52(11.1 \%)$ & $8(8.0 \%)$ & & $22(10.2 \%)$ & & $16(11.6 \%)$ & \\
\hline
\end{tabular}

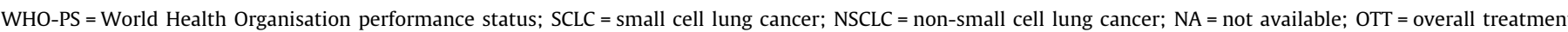
time; $\mathrm{MED}=$ mean esophagus dose; $\mathrm{MAXED}=$ maximum esophagus dose $; \mathrm{CTC}=$ common toxicity criteria.

Table 2

Odds ratio's for developing dysphagia.

\begin{tabular}{llllc}
\hline Variable & Coefficient & Odds ratio & $95 \% \mathrm{CI}$ & $P$ \\
\hline Age & -0.03 & 0.97 & $0.95-0.99$ & 0.003 \\
Gender & & & & 0.011 \\
Male & & Ref. & & \\
Female & 0.50 & 1.65 & $1.12-2.43$ & \\
WHO-PS & & & & 0.012 \\
$0-1$ & & Ref. & & \\
$\geqslant 2$ & 0.57 & 1.76 & $1.13-2.75$ & \\
Chemotherapy & & & & $<0.001$ \\
No/sequential & & Ref. & & \\
Concurrent & 0.93 & 2.53 & $1.64-3.91$ & \\
MED & 0.06 & 1.06 & $1.04-1.09$ & $<0.001$ \\
MAXED & 0.03 & 1.03 & $1.01-1.05$ & 0.0002 \\
OTT & -0.06 & 0.94 & $0.92-0.96$ & $<0.001$ \\
\hline
\end{tabular}

$\mathrm{CI}=$ confidence interval; WHO-PS = World Health Organisation performance status; $\mathrm{MED}=$ mean esophagus dose; MAXED = maximum esophagus dose; OTT = overall treatment time.

therefore, included both in our analysis and our results indeed show that MED as well as MAXED are statistically significant predictors for dysphagia.

Several studies have found an increase in esophageal toxicity if the radiotherapy treatment was delivered in a short time period by administering radiotherapy twice daily or by applying hyperfractionated radiotherapy schemes $[1,25]$ In line with these studies, we found that shorter OTT was significantly associated with higher dysphagia scores.

Many studies have found a relationship between chemotherapy and dysphagia. While sequentially given chemotherapy did not increase the risk of dysphagia, concurrent chemotherapy was consistently associated with a higher risk $[10,11]$. Our results are comparable, showing an increased risk for patients treated with concurrent chemo-radiation.

We found several patient characteristics which were prognostic for the development of dysphagia. Although most studies reported no correlation between gender and dysphagia $[1,4,8]$ WernerWasik et al. did find an association between female gender and increased esophagus toxicity [9]. Our results also indicate that females have a higher risk for developing dysphagia.

Age is another potential risk factor for which conflicting findings have been published. In some studies age was associated with radiation-induced dysphagia, but it was not reported whether this was a positive or negative correlation [1,3], while in other studies no relationship was found $[4,6-8]$. Although we have corrected for all known confounders, such as gender, performance status, chemotherapy and radiation dose, we found a lower risk with increasing age. A possible explanation for this finding may be that the morphological and biochemical changes in the mucosa of elderly people makes the mucosa less vulnerable for radiation damage, but this is not supported by animal data [26]. Other, at present unknown factors, which influence the severity of dysphagia and are associated with age, might explain our results. More research is needed to elucidate the underlying mechanism.

In our study, a worse performance status was associated with a higher risk of developing dysphagia while other studies reported that the association between performance status and esophageal toxicity was statistically not significant $[4,5,7,8]$. This might be explained by the fact that these studies included a very low number (ranging from 9 to 17) of patients with a bad performance status compared to our study population, which included 100 patients $(21 \%)$ with a performance status $\geqslant 1$. 
Points

age

overall treatment time

mean esophagus dose

max esophagus dose

chemotherapy

gender

WHO-PS

Total Points

Prob dysphagia $>=2$

Prob dysphagia $>=3$


\begin{tabular}{rlllllllll}
\hline 60 & 1 & 1 & 1 & 1 & 1 & 1 & & 15 \\
\hline & 55 & 50 & 46 & 40 & 35 & 30 & 25 & 20 & 15
\end{tabular}

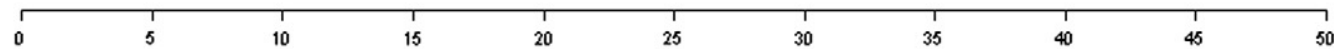

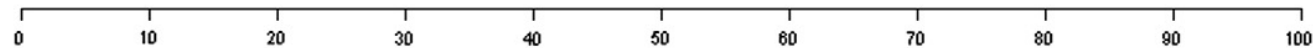
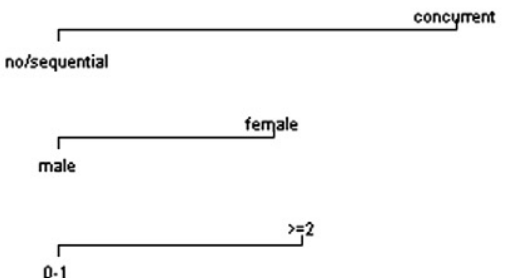

$>=2$

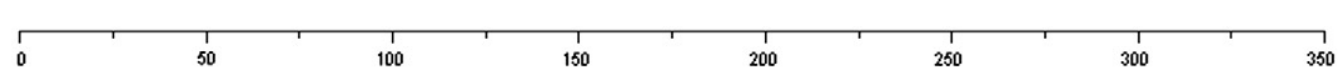

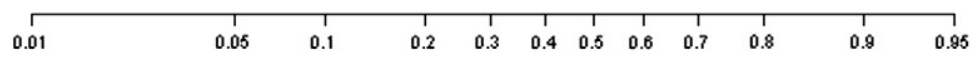

\begin{tabular}{ccccccccc}
\hline 0.01 & & 1 & 1 & 1 & 1 & 1 & 1 & \\
& 0.05 & 0.1 & 0.2 & 0.3 & 0.4 & 0.5 & 0.8 & 0.7
\end{tabular}

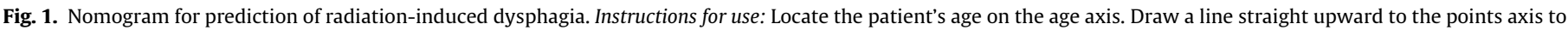

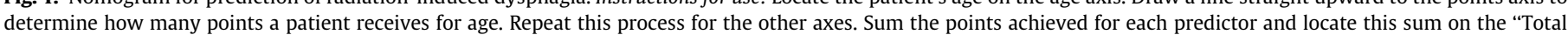
points" axis. Draw a line straight down to assess the probability for this patient.

The predictive ability of the doctors at time point 1 was very limited, resulting in an AUC of 0.53 , while the model performed well with an AUC of $0.75(p=0.012)$. Although the performance was better at time point 2 , when the dosimetric information was available, it was still lower than the model performance. This is in line with studies investigating the ability of physicians to predict survival [27]. In general, statistical models predict more accurately the outcome than humans, probably because models can take into account many parameters at the same time and they are not susceptible to a variety of human biases [28]. It has been shown that these statistical tools can indeed improve the quality of medical decision making $[28,29]$.

While the decision to limit our analysis to two dosimetric parameters can be justified by taking into account results from other studies [2], it can not be excluded that other dosimetric parameters or a combination of parameters might yield a better model. In addition, acute dysphagia often occurs during the course of therapy when the final overall dose and OTT is not yet reached [11]. Although MED, MAXED and OTT were statistically significant, it is possible that the rapidity of dose accumulation is more important than these factors [11]. However, to our knowledge, no current models account for the course of a complication relative to the dose delivered. In future this should be incorporated into the model.

The current prediction model is based on a heterogeneous patient group. Although it is of utmost importance to include uniform groups of patients in clinical trials, where the aim is to assess the value of a specific (new) treatment, this is certainly not the case if one wants to develop a predictive model. To assess the prognostic value of variables heterogeneity in terms of patient and treatment characteristics is essential [30]. Moreover, the model is intended to be applicable for all lung cancer patients treated with radiotherapy and, therefore, all patients should also be included in the model building process. We would like to emphasize that a model can only be applied safely to other groups of patients if these groups are comparable to the study population, in terms of patient as well as treatment characteristics. For example, we do not advise to apply our model to patients treated with stereotactic radiotherapy. At our institute data are being collected for all lung cancer patients, including those who are treated with intensitymodulated radiotherapy (IMRT) or stereotactic radiotherapy. When these subpopulations are large enough, the data will be included in the statistical analysis to update the model. This will finally lead to a prediction model that can be applied to the whole patient population.

Although concurrent chemotherapy and radiotherapy are considered standard of care for stage III NSCLC patients, it has been shown in a prospective population-based study that many patients were not eligible for concurrent chemo-radiation and thus received sequential chemo-radiation [31]. To enhance the applicability of our model we, therefore, also included patients receiving sequential chemotherapy and radiotherapy.

In future our model could be further improved if information about individual radio-sensitivity would become available. At the moment genome wide association studies (GWAS) to identify single nucleotide polymorphisms (SNP's) associated with toxicity are being conducted and this approach might lead to the development of a clinically useful pretreatment profile test [32]. However, the results of these ongoing studies are to be awaited. Our current model consists of variables that are easily obtained. Moreover, taking into account the limited ability of physicians to estimate 



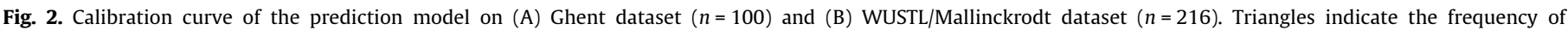

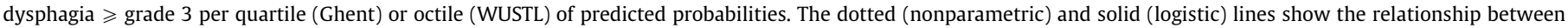
observed and predicted probabilities. Ideally, these lines equal the dashed line. The vertical lines at the bottom indicate the distribution of the predicted probabilities.

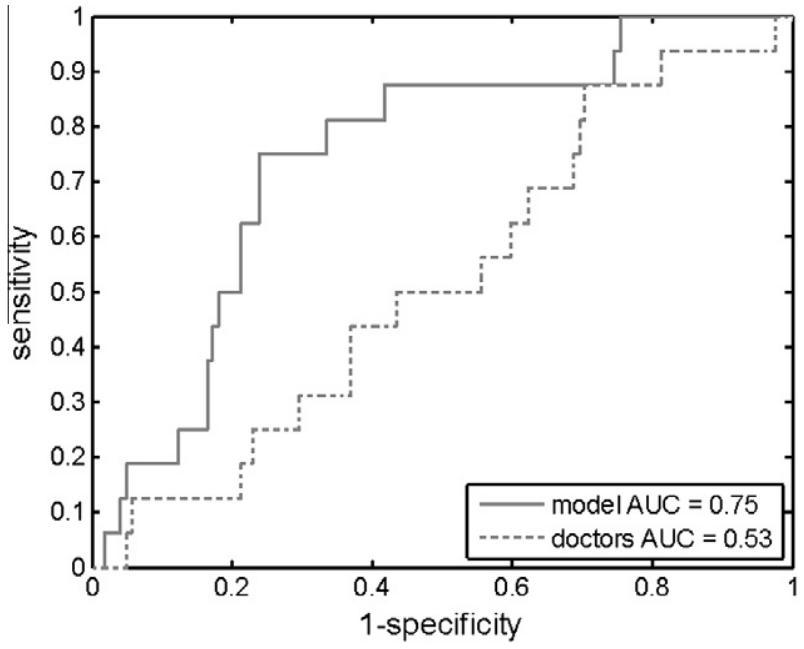

Fig. 3. Comparison between physicians' prediction and model prediction in terms of AUC $(n=138)$. the risk of dysphagia, this model is without doubt an attractive tool to use in daily clinical practice.

\section{Conclusions}

To our knowledge, this is the first published prediction model for radiation-induced dysphagia. The performance of the model, c-statistic of 0.77 , was good. In addition, the external validation was successful and the model outperformed the clinicians' predictive ability. Therefore, this model can offer assistance in treatment decision making. Adequate measures, such as placement of feeding tubes, intensified dietician support or in the future administration of preventive medication, could be taken if patients are at high risk for developing dysphagia. Based on the predicted probability of developing severe dysphagia patients could be considered for radiation dose escalation to improve tumor control probability, with or without taking pre-emptive measures.

\section{Conflict of interest notification}

No actual or potential conflicts of interest exist for the authors of this manuscript. 


\section{Acknowledgements}

The authors thank Carla Vandenabeele, datamanager, Zorgprogramma Oncologie UZ Gent (ZOG), Elke Van Schoote, MD, St. Elisabeth Hospital Zottegem, and Hugo Ottevaere, MD, ASZ Oudenaarde, for their support in the acquisition of the data.

This study was performed within the framework of CTMM, the Center for Translational Molecular Medicine. AIRFORCE project (Grant 030-103).

The acquisition of the data of Washington University in St. Louis, Department of Radiation Oncology, St. Louis, USA was partially supported by US NIH Grant R01 85181 (J.O.D) and K25 (I.E.N.).

\section{Appendix. Supplementary data}

Supplementary data associated with this article can be found, in the online version, at doi:10.1016/j.radonc.2010.09.028.

\section{References}

[1] Ahn SJ, Kahn D, Zhou S, et al. Dosimetric and clinical predictors for radiationinduced esophageal injury. Int J Radiat Oncol Biol Phys 2005;61:335-47.

[2] Rose J, Rodrigues G, Yaremko B, Lock M, D'Souza D. Systematic review of dosevolume parameters in the prediction of esophagitis in thoracic radiotherapy. Radiother Oncol 2009;91:282-7.

[3] Belderbos J, Heemsbergen W, Hoogeman M, Pengel K, Rossi M, Lebesque J. Acute esophageal toxicity in non-small cell lung cancer patients after high dose conformal radiotherapy. Radiother Oncol 2005;75:157-64.

[4] Bradley J, Deasy JO, Bentzen S, El-Naqa I. Dosimetric correlates for acute esophagitis in patients treated with radiotherapy for lung carcinoma. Int J Radiat Oncol Biol Phys 2004;58:1106-13.

[5] Kim TH, Cho KH, Pyo HR, et al. Dose-volumetric parameters of acute esophageal toxicity in patients with lung cancer treated with threedimensional conformal radiotherapy. Int J Radiat Oncol Biol Phys 2005;62:995-1002.

[6] Maguire PD, Sibley GS, Zhou SM, et al. Clinical and dosimetric predictors of radiation-induced esophageal toxicity. Int $\mathrm{J}$ Radiat Oncol Biol Phys 1999;45:97-103.

[7] Singh AK, Lockett MA, Bradley JD. Predictors of radiation-induced esophageal toxicity in patients with non-small-cell lung cancer treated with threedimensional conformal radiotherapy. Int J Radiat Oncol Biol Phys 2003;55:337-41.

[8] Wei X, Liu HH, Tucker SL, et al. Risk factors for acute esophagitis in non-smallcell lung cancer patients treated with concurrent chemotherapy and threedimensional conformal radiotherapy. Int J Radiat Oncol Biol Phys 2006;66:100-7.

[9] Werner-Wasik M, Pequignot E, Leeper D, Hauck W, Curran W. Predictors of severe esophagitis include use of concurrent chemotherapy, but not the length of irradiated esophagus: a multivariate analysis of patients with lung cancer treated with nonoperative therapy. Int J Radiat Oncol Biol Phys 2000;48:689-96.

[10] Bradley J, Movsas B. Radiation esophagitis: predictive factors and preventive strategies. Semin Radiat Oncol 2004;14:280-6.

[11] Werner-Wasik M, Yorke E, Deasy J, Nam J, Marks LB. Radiation dose-volume effects in the esophagus. Int J Radiat Oncol Biol Phys 2010;76:S86-93.

[12] Chapet O, Kong FM, Lee JS, Hayman JA, Ten Haken RK. Normal tissue complication probability modeling for acute esophagitis in patients treated with conformal radiation therapy for non-small cell lung cancer. Radiother Oncol 2005; 77:176-81.
[13] De Ruysscher D, Wanders S, van Haren E, et al. Selective mediastinal node irradiation based on FDG-PET scan data in patients with non-small-cell lung cancer: a prospective clinical study. Int J Radiat Oncol Biol Phys 2005;62:988-94.

[14] ICRU Report 50: Prescribing, Recording, and Reporting Photon Beam Therapy. Bethesda, MD: International Commission on Radiation Units and Measurements; 1993.

[15] Maastricht Radiation Oncology, The Netherlands. Radiotherapy for NSCLC to an individualized MLD (BRONC MLD). Bethesda (MD): National library of medicine (US) [In: ClinicalTrials.gov [internet]]. Available from: http:// clinicaltrials.gov/show/NCT00573040 NLM identifier: NCT00573040; 2009 [cited 15.09.09].

[16] van Baardwijk A, Bosmans G, Boersma L, et al. Individualized radical radiotherapy of non-small-cell lung cancer based on normal tissue dose constraints: a feasibility study. Int J Radiat Oncol Biol Phys 2008;71:1394-401.

[17] van Baardwijk A, Wanders S, Boersma L, et al. Mature results of an individualized radiation dose prescription study based on normal tissue constraints in stage I-III non-small cell lung cancer. J Clin Oncol 2010;28:1380-6.

[18] Maastricht Radiation Oncology, The Netherlands. Concurrent chemo-radiation for NSCLC to an individualized MLD. Bethesda (MD): National library of medicine (US) [In: ClinicalTrials.gov [internet]]. Available from: http:// clinicaltrials.gov/show/NCT00572325 NLM identifier: NCT00572325; 2009 [cited 15.09.09].

[19] De Ruysscher D, Bremer RH, Koppe F, et al. Omission of elective node irradiation on basis of CT-scans in patients with limited disease small cell lung cancer: a phase II trial. Radiother Oncol 2006;80:307-12.

[20] van Loon J, De Ruysscher D, Wanders R, et al. Selective nodal irradiation on basis of (18)FDG-PET scans in limited-disease small cell lung cancer: a prospective study. Int J Radiat Oncol Biol Phys 2009.

[21] Bentzen SM, Dorr W, Anscher MS, et al. Normal tissue effects: reporting and analysis. Semin Radiat Oncol 2003;13:189-202.

[22] El Naqa I, Bradley J, Blanco AI, et al. Multivariable modeling of radiotherapy outcomes, including dose-volume and clinical factors. Int J Radiat Oncol Biol Phys 2006;64:1275-86

[23] Harrell Jr FE, Lee KL, Mark DB. Multivariable prognostic models: issues in developing models, evaluating assumptions and adequacy, and measuring and reducing errors. Stat Med 1996;15:361-87.

[24] Rodriguez N, Algara M, Foro P, et al. Predictors of acute esophagitis in lung cancer patients treated with concurrent three-dimensional conformal radiotherapy and chemotherapy. Int J Radiat Oncol Biol Phys 2009:73:810-7.

[25] De Ruysscher D, Dehing C, Bremer RH, et al. Maximal neutropenia during chemotherapy and radiotherapy is significantly associated with the development of acute radiation-induced dysphagia in lung cancer patients. Ann Oncol 2007;18:909-16.

[26] Landuyt W, Van der Schueren E. Effect of age on the radiation-induced repopulation in mouse lip mucosa. Strahlenther Onkol 1991;167:41-5.

[27] Chow E, Davis L, Panzarella T, et al. Accuracy of survival prediction by palliative radiation oncologists. Int J Radiat Oncol Biol Phys 2005;61:870-3.

[28] Bornstein BH, Emler AC. Rationality in medical decision making: a review of the literature on doctors' decision-making biases. J Eval Clin Pract 2001;7:97-107.

[29] Liu J, Wyatt JC, Altman DG. Decision tools in health care: focus on the problem, not the solution. BMC Med Inform Decis Mak 2006;6:4

[30] Lambin P, Petit SF, Aerts HJ, et al. The ESTRO Breur lecture 2009. From population to voxel-based radiotherapy: exploiting intra-tumour and intraorgan heterogeneity for advanced treatment of non-small cell lung cancer. Radiother Oncol 2009;96:145-52.

[31] De Ruysscher D, Botterweck A, Dirx M, et al. Eligibility for concurrent chemotherapy and radiotherapy of locally advanced lung cancer patients: a prospective, population-based study. Ann Oncol 2009;20:98-102.

[32] Barnett GC, West CM, Dunning AM, et al. Normal tissue reactions to radiotherapy: towards tailoring treatment dose by genotype. Nat Rev Cancer 2009;9:134-42. 